\title{
A tension assessment model for digital twins of continuous rolling processes
}

\author{
Christian Overhagen ${ }^{1, *}$
}

September 19, 2021

\begin{abstract}
The paper deals with the calculation of interstand tensions in continuous rolling mills for flat and long products. A fast calculation method for the interstand tensions from measurable process quantities is a critical point to enable the construction of digital twins for the rolling process, which must be adjusted to the real-world tension behaviour of the production system. It is straightforward to calculate the effects of the tensions on roll forces, torques and the strip or bar velocity. However, the inverse problem of calculating the acting interstand tensions including their effects from the process parameters is of much greater interest but also of a higher complexity, because the interactions between all of the stands in the continuous rolling mill must be taken into account. The paper presents a mathematical model to solve the inverse problem by subsequent linearization of the tensions influences in the rolling mill. Extra nonlinearities are taken into account by modeling the tension-dependent spread by an empirical model. The overall model is solved by an iteration method to yield a fully compatible solution for the constant volume flux as well as the force and torque equilibria in the roll gaps. Results are shown for the tension distributions in strip and rod mills. The results indicate that the present friction conditions and the spreading behaviour of the rolled material have a high impact on the tension distributions.
\end{abstract}

Key words: Interstand Tensions, Wire Rod Rolling, Strip Rolling

\section{Contents}

1 Introduction

2 Method for the inverse calculation of interstand tensions 3

2.1 Calculation of interstand tensions in plane strain flat rolling . . . . . . . . . . . . . . . 3

2.2 Numerical algorithm of the model . . . . . . . . . . . . . . . . . . . . . 7

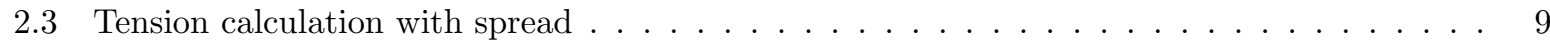

2.4 Effects of interstand tension in round-oval-round pass sequences . . . . . . . . . . . . . 10

3 Results of the model for industrial rolling processes 11

3.1 Finishing train of a hot strip mill . . . . . . . . . . . . . . . . . . . . . 12

3.1.1 Influence of a transfer bar height variation on interstand tensions . . . . . . . . . . 12

3.1.2 Friction influence on the interstand tension distribution . . . . . . . . . . . . . 13

3.1.3 The influence of the rolling temperature on interstand tensions . . . . . . . . . . 13

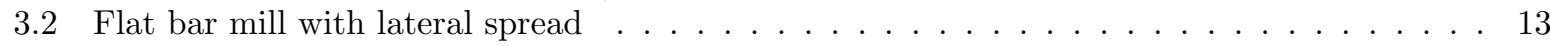

3.3 Single-strand wire $\operatorname{rod} \operatorname{mill} \ldots \ldots \ldots \ldots \ldots \ldots$

4 Discussion $r 2$

5 References $\quad \mathbf{2 2}$

${ }^{1}$ Institute for Technologies of Metal, University of Duisburg-Essen, Friedrich-Ebert-Str. 12, 47119 Duisburg, Germany

${ }^{*}$ Corresponding author, email: christian.overhagen@uni-due.de. 


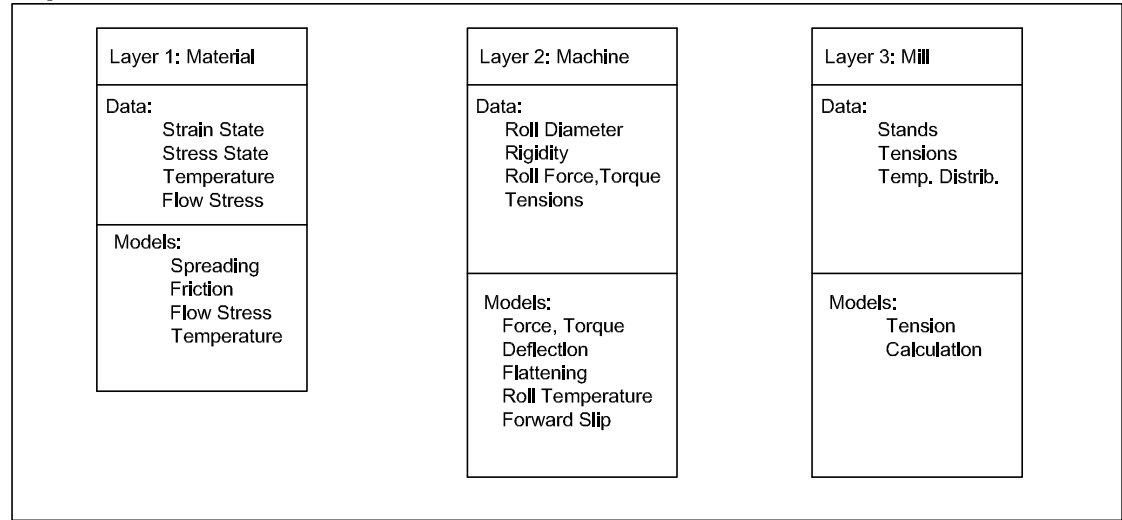

Real-World System

\begin{tabular}{|c|c|c|}
\hline Temperature & Roll Speed & Production \\
\hline Section Shape & Material Speed & |Capacity \\
\hline Roll Force & Roll Force & \\
\hline Roll Torque & Roll Temp. & \\
\hline
\end{tabular}

Figure 1: Schematic representation of the structure of a digital twin for continuous rolling with key parameters from the physical system

\section{Introduction}

The ongoing industrial digitization calls for digital twins of manufacturing processes. The digital twin of an industrial rolling process facilitates data and models about the deformation tools and deformed material in a way that it behaves like the physical process and data can be exchanged between the digital and physical twin. A digital twin for continuous rolling mills could be constructed as given in Fig. 1. The three layers of material, machine and mill (consisting of several machine units) are linked together by a number of interdepencies. It is a typical and very important feature of the digital twin to continuously exchange data with its real world twin. This data serves as input and validation data for the models incorporated in the digital twin layers, on the other hand calculated model data are used supply nonmeasurable information needed to adjust the real-world production process. The constant adjustment of the two twins to one another is a typical feature of the digital twin solution. From Fig. 1, we can see that the interstand tension distribution is a parameter of the mill layer and therefore responsible for the coupling of several rolling stands, but it influences also the other layers by altering roll force and torque (machine layer) as well as the stress state and spreading (material layer). The present paper therefore deals with the interstand tension model as being a critical factor to enable digital twinning of the rolling process.

A calculation of the effects of the interstand tensions on the stress distribution for plane strain rolling processes can be easily carried out using slab method approaches of rolling, but the backward-calculation of the interstand tensions that act in a specific rolling processes is much more complicated. The problem gains extra complexity, when a non-plane strain rolling process with lateral spread is considered, which is especially the case for rolling processes of long products.

The presented calculation method is based on a stepwise linearization of the tension influences on the rotational roll speeds, based on the basic equations of the rolling theory. Assembled for all stands of the rolling mill, a linear system of equation follows which is solved in order to calculate an approximation to the actual acting tensions. This methodology was chosen to attain a mathematical solution which is consistent with the analytical rolling theory which has proven to deliver a realistic assessment of the tension influences in a rolling process in order to supply the necessary information to ensure close products tolerances and high operational safety to the physical process. 


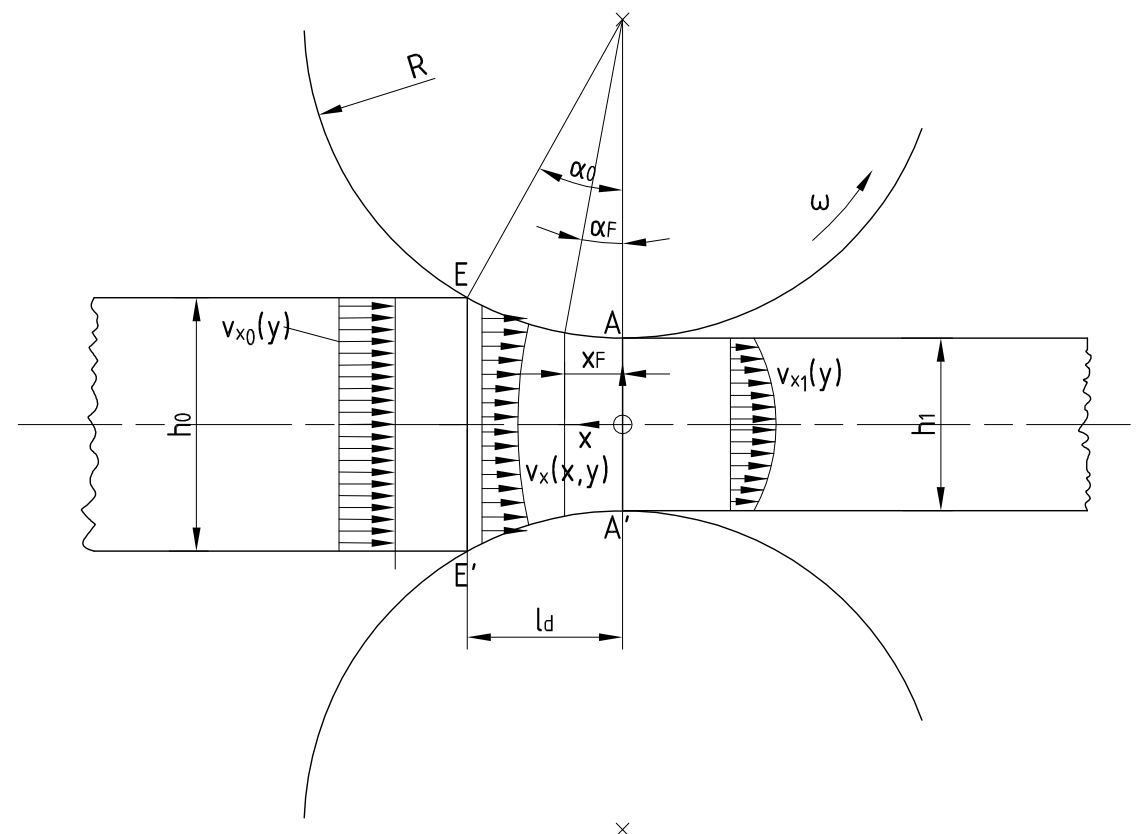

Figure 2: Schematic representation of the roll gap in flat rolling [9]

\section{Method for the inverse calculation of interstand tensions}

In the present analysis, von Karman's theory of rolling is employed in the form given by Alexander [1] and later employed by Chen et al. [2]. For the flat rolling case treated by Alexander, a rectangular sheet or strip section is reduced from the initial height $h_{0}$ to the final height $h_{1}$ by passing through a gap formed between two cylindrical rollers as shown in Fig. 2.

Von Karman's approach of a force equilibrium at the strip element in the roll gap yields an ordinary differential equation, which is expressed in the most general form with the horizontal stress $\sigma_{x}$, the strip height $h$, the normal stress between rolls and rolled material $\sigma_{N}$, the frictional shear stress $\tau_{F}$ and the roll surface inclination angle $\alpha$ :

$$
\frac{d\left(\sigma_{x} h\right)}{d x}=2\left(\sigma_{N} \tan \alpha \pm \tau_{F}\right)
$$

The core of the present work is the backward calculation of the interstand tensions which are acting in a certain rolling configuration. The principle idea behind this model could be applied to any rolling model based on v. Karman's ODE. In the present analysis, we will utilize Alexander's rolling theory because it is a systematic numerical scheme for the integration of Eqn. (2.1).

\subsection{Calculation of interstand tensions in plane strain flat rolling}

The numerical solution of Alexander's differential equation yields the stress distribution from which a neutral point can be found, indicating the position of a zero relative velocity in the roll gap and coupling the frictional shear stress distribution to the velocity distribuion as shown in Fig. 3. The neutral point represents the location of the peak stress in the vertical pressure distribution, and also conincides with the position where the horizontal component of the circumferential roll velocity is equal to the horizontal stock velocity.

The calculated velocity and stress distributions allow the conclusion that for a given mill setup, the angular velocity $\omega$ of the rolls in a single mill stand is influenced by the front and back tensions. The back tension of a mill stand $i$ will now be denoted by $t_{0, i}$, the front tension will be denoted by $t_{1, i}$, respectively.

Figure 4 shows three continuous roll gaps exemplarily. Generally, the front tension of a mill stand $i$ is equivalent to the back tension of stand $i+1$, i.e. $t_{1, i}=t_{0, i+1}$. For each mill stand $i$ in a continuous 

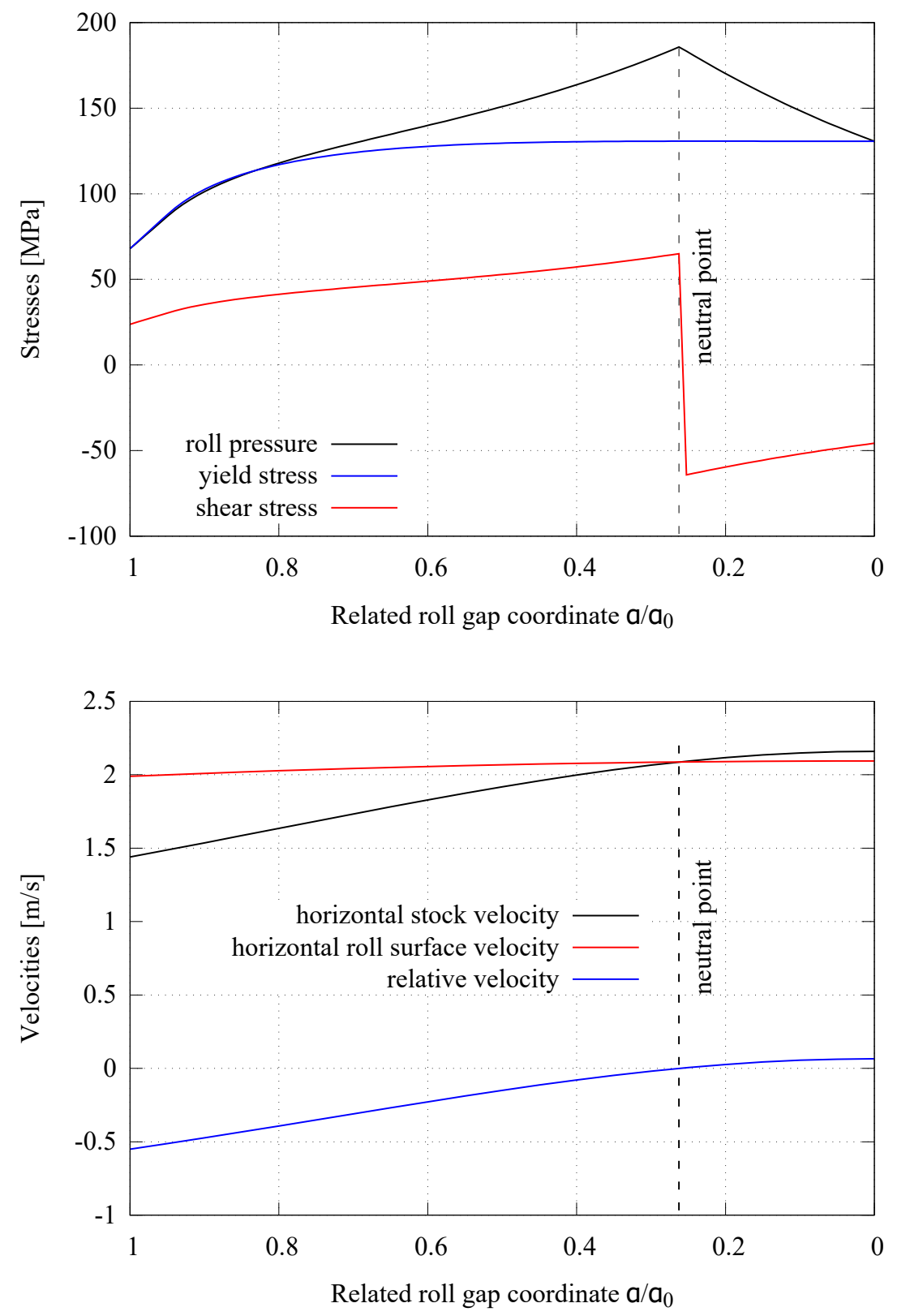

Figure 3: Kinematic-static coupling in the roll gap 


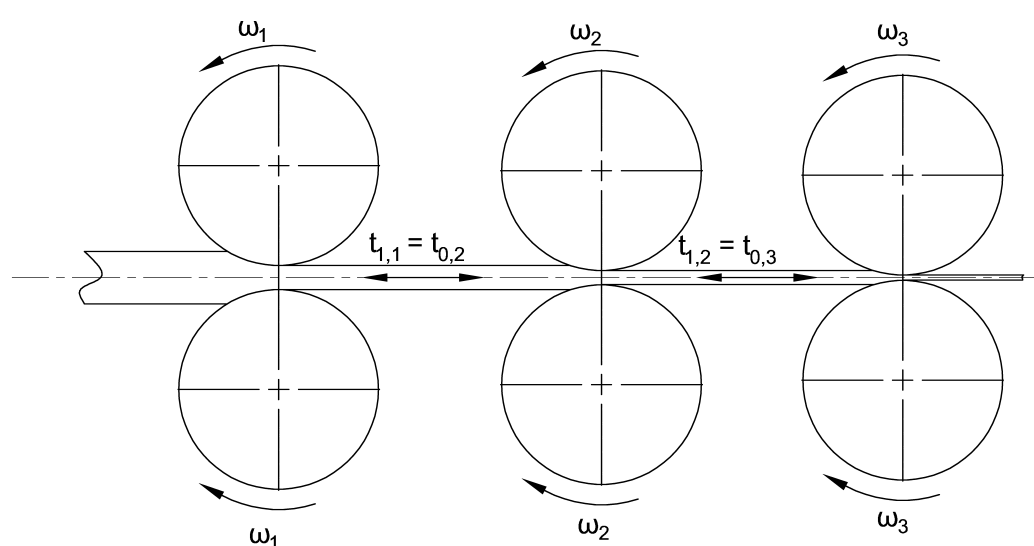

Figure 4: Three roll gaps of a continuous rolling mill

arrangement, we can formulate a nonlinear equation relating the back and front tension as well as the volume flux to the angular velocity of the roll:

$$
\omega_{i}=f\left(t_{0}, t_{1}, \dot{V}\right)
$$

For a rolling mill with $N$ mill stands, a system of $N$ nonlinear equations must be solved to find the $N-1$ unknown tensions $t_{i}$ and the volume flux $\dot{V}$. It may however be convenient to express the nonlinear system as in Eqn. (2.2) in a linearized form to find a preliminary approximate solution. Assuming linear relationships for the effects of the tensions $t_{0, i}$ and $t_{1, i}$ on the angular velocity $\omega$ of the rolls, we can write for a mill stand $i$ :

$$
\omega_{i}=\omega_{0, i}+a_{i} t_{0, i}+b_{i} t_{1, i}
$$

In Eqn. (2.3), $\omega_{0, i}$ is the designed angular roll velocity for a reference case without tensions. The coefficients $a_{i}$ and $b_{i}$ are influence parameters for the back and front tensions. We can express this relation for the variation of the angular roll velocity $\Delta \omega_{i}$ due to variation of the interstand tensions $\Delta t_{0, i}$ and $\Delta t_{1, i}$ :

$$
\Delta \omega_{i}=a_{i} \Delta t_{0, i}+b_{i} \Delta t_{1, i}
$$

Furthermore, Eqn. (2.4) is rewritten for the change of the roll speed difference between two successive mill stands $i$ and $i+1$ :

$$
\Delta \omega_{i+1}-\Delta \omega_{i}=\left(a_{i+1}-b_{i}\right) \Delta t_{1, i}-a_{i} \Delta t_{0, i}+b_{i+1} \Delta t_{1, i+1}
$$

Eqn. (2.5) describes the coupling between two successive mill stands due to the acting tensions. Therefore, a system of linear equations can be set up to calculate approximations to the unknown tension differences, which cause the known differences of the roll speeds. It represents the linear equation system with $N-1$ equations and unknowns, where $N$ is the total number of mill stands in the continuous rolling mill. The back tension of the first stand, was well as the front tension of the last stand is generally treated as zero.

$$
\mathbf{A t}=\mathbf{w}
$$


Eqn. (2.6) shows the structure of the linear equation system that must be solved for the tensions. The coefficient matrix $\mathbf{A}$ for $N$ stands is given as:

$$
\mathbf{A}=\left[\begin{array}{cccccc}
a_{2}-b_{1} & b_{2} & & & & \\
-a_{2} & \ddots & \ddots & & & \\
& \ddots & \ddots & \ddots & & \\
& & -a_{i} & a_{i+1}-b_{i} & b_{i+1} & \\
& & & \ddots & \ddots & b_{N-1} \\
& & & & -a_{N-1} & a_{N}-b_{N-1}
\end{array}\right]
$$

The right hand side vector $\mathbf{w}$ comprises the changes in the roll speed differences between two subsequent mill stands, relative to the initial reference state:

$$
\mathbf{w}=\left[\begin{array}{c}
\Delta \omega_{2}-\Delta \omega_{1} \\
\vdots \\
\Delta \omega_{i+1}-\Delta \omega_{i} \\
\vdots \\
\Delta \omega_{N}-\Delta \omega_{N-1}
\end{array}\right]
$$

In Eqn. (2.8), $\Delta \omega_{i}$ is the change of the angular roll velocity $\omega_{i}$ of mill stand $i$ relative to the original angular velocity of the reference configuration. The remaining problem is the definition of the influence parameters $a_{i}$ and $b_{i}$ for each mill stand $i$. These are the partial derivatives of the angular velocity with respect to the back and front tension stresses.

With reference to $(2.3)$, we write:

$$
\begin{aligned}
a_{i} & =\frac{\partial \omega_{i}}{\partial t_{0, i}} \\
b_{i} & =\frac{\partial \omega_{i}}{\partial t_{1, i}}
\end{aligned}
$$

These differentials can be written as a composite function comprising a kinematic and a static part. We can apply the chain rule to Eqns. (2.9) and (2.10) and arrive at the following equations:

$$
\begin{aligned}
a_{i} & =\frac{\partial \omega_{i}}{\partial t_{0, i}}=\frac{\partial \omega_{i}}{\partial \alpha_{N, i}} \frac{\partial \alpha_{N, i}}{\partial t_{0, i}} \\
b_{i} & =\frac{\partial \omega_{i}}{\partial t_{1, i}}=\frac{\partial \omega_{i}}{\partial \alpha_{N, i}} \frac{\partial \alpha_{N, i}}{\partial t_{1, i}}
\end{aligned}
$$

The kinematic derivative $\frac{\partial \omega_{i}}{\partial \alpha_{N, i}}$ can be worked out by help of the volume flux. For the angular velocity as a function of the neutral angle $\alpha_{N}$, we can write with the volume flux $\dot{V}$, the roll radius $R$ and the exit height and width $h_{1}$ and $b_{1}$ :

$$
\omega\left(\alpha_{N}\right)=\frac{\dot{V}}{b_{1} R\left[h_{1}+2 R\left(1-\cos \alpha_{N}\right)\right] \cos \alpha_{N}}
$$

Deriving this equation with respect to $\alpha_{N}$, we arrive at the final kinematic equation:

$$
\frac{\partial \omega}{\partial \alpha_{N}}=\frac{\dot{V} \sin \alpha_{N}\left(2 R+h_{1}-4 R \cos \alpha_{N}\right)}{b_{1} R \cos ^{2} \alpha_{N}\left(2 R+h_{1}-2 R \cos \alpha_{N}\right)^{2}}
$$

The static part comprises two equations describing the influences of the front and back tensions on the neutral angle which can be found from the rolling model. For a more simplified rolling model we could 
find analytical expressions for the static part, but these types of rolling models do not allow the discussion of the friction influence as they are limited to constant sticking friction conditions. For the Alexander model used in the present analysis, the determination of the neutral angle requires a numerical solution of the rolling model ODE. We can treat the neutral angle as a function of the entry and exit tensions, $\alpha_{N}=\alpha_{N}\left(t_{0}, t_{1}\right)$. Then it follows:

$$
\begin{aligned}
\frac{\partial \alpha_{N}}{\partial t_{0}} & \approx \frac{\alpha_{N}\left(t_{0}+\varepsilon, t_{1}\right)-\alpha_{N}\left(t_{0}-\varepsilon, t_{1}\right)}{2 \varepsilon} \\
\frac{\partial \alpha_{N}}{\partial t_{1}} & \approx \frac{\alpha_{N}\left(t_{0}, t_{1}+\varepsilon\right)-\alpha_{N}\left(t_{0}, t_{1}-\varepsilon\right)}{2 \varepsilon}
\end{aligned}
$$

With these equations developed, it is now posssible to calculate the interstand tension changes that arise from certain changes to the mill setup and rolling parameters by a numerical algorithm.

\subsection{Numerical algorithm of the model}

Since the interstand tensions and the volume flux of the rolling process are interdependent, an iterative calculation scheme must be applied. First, we can apply the rolling model to the given pass schedule in order to calculate the angular roll velocities that match a given sequence of interstand tensions, which we call the reference configuration or the design state. Later we will calculate the differences in tension that result from changes to the reference configuration.

This reference configuration is then used to compute the tension influence coefficients $a_{i}$ and $b_{i}$ for each mill stand $i$. Afterwards, the coefficient matrix acc. to Eqn. (2.7) is built using these influence coefficients. To calculate the tension variations arising due to variations of the roll speeds, we can setup the right hand side of Eqn. (2.6) using the known velocity differences. The solution of the linear system then yields a first approximation to the interstand tensoin deviations in relation to the reference configuration.

As the model is non-linear i.e. the influence coefficients depend upon the tensions, these first approximations of interstand tensions will still lead to angular velocities deviating from the actual ones. For numerical stability, we update the tensions of the reference configuration with the calculated tension deviations with a successive underrelaxation factor $f_{R}$ :

$$
t_{i}=t_{i, \text { old }}+f_{R} \Delta t_{i}
$$

In Eqn. (2.18), $f_{R}$ is in the order of magnitude of $f_{R} \approx 0.5$.

The approximated tensions are used as a new reference configuration and the influence coefficients are recalculated for the next iteration. As Figure 5 shows, the linear system is solved again for the new reference configuration and the residuals are recalculated. These steps are repeated iteratively. Before a new iteration is entered, the volume flux is corrected to meet the calculated exit strip velocity of the last stand according to:

$$
v=v-b_{e} h_{e} R_{n}\left(\omega_{0, n}-\omega_{n}\right)\left(1+\kappa_{n}\right) f_{R}
$$

The relaxation factor $f_{R}$ in Eqn. (2.19) is the same as in Eqn. (2.18). The values $h_{e}, b_{e}$ and $R_{n}$ are the strip thickness, strip width and the roll radius of the final pass, $\kappa_{n}$ is the forward slip of the final pass. $\omega_{n}$ is the calculated angular roll velocity of the final pass, $\omega_{0, n}$ is the intended angular roll velocity. The iterative process is repeated until the deviation of the calculated angular velocities from the originally intended ones is smaller than a predefined tolerance value. Additionally, a relative convergence criterion is observed to ensure the calculated tensions in the last 5 iterations do not deviate significantly. After the iterative calculation is finished, the final interstand tensions and the final volume flux have been found and all other rolling parameters can be calculated from the rolling model using these values. 


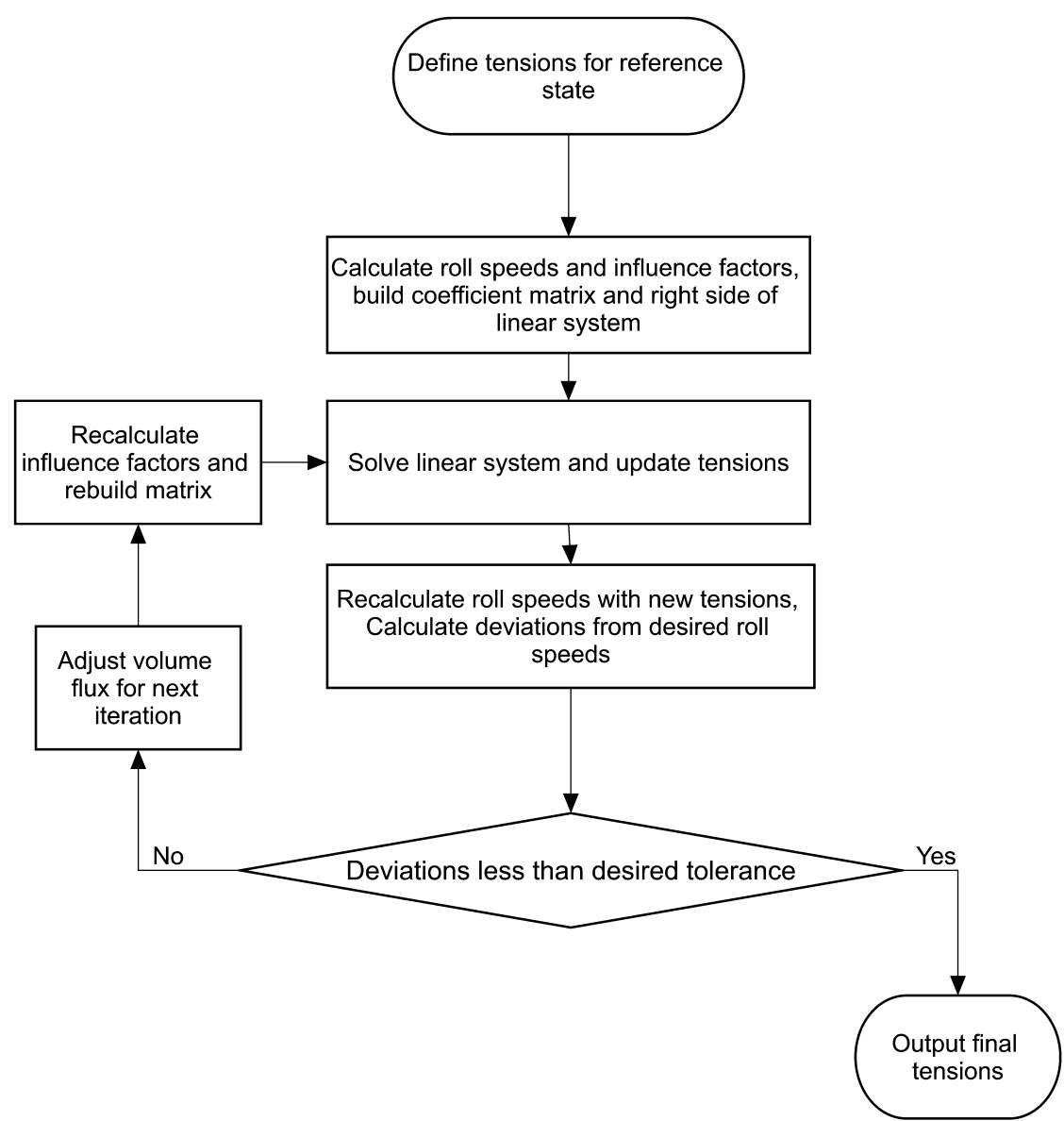

Figure 5: Numerical algorithm for the analytical model 


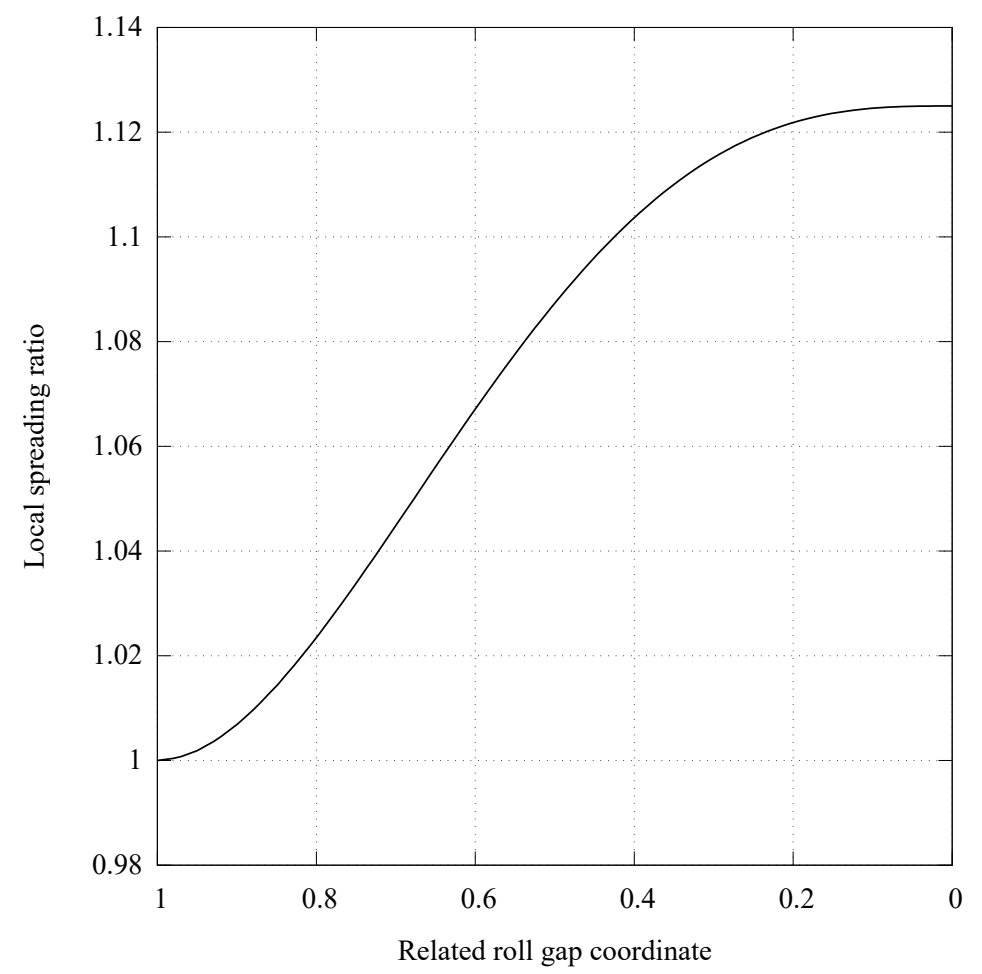

Figure 6: Domanti's spread function for a rectangular flat pass, entry: $40 \mathrm{~mm}$ square, exit height $h_{1}=30 \mathrm{~mm}$, roll diameter $d=600 \mathrm{~mm}$

\subsection{Tension calculation with spread}

If lateral spread of a non-neglegible magnitude is present in the rolling process, the calculation of the roll speeds and interstand tensions gains a higher amount of nonlinearity. From the volume flux in rolling, we can write for the angular roll velocity when we express the rectangular cross sections by the product $A=h b$ :

$$
\omega=\frac{h_{1} b_{1} v_{1}}{R \cos \alpha_{N} h_{N} b_{N}}
$$

In Eqn. (2.20), $b_{N}$ is the width of the rolled material at the neutral plane, $b_{N}=b\left(\alpha_{N}\right)$. To evaluate this equation, we need to know the width function $b(\alpha)$ in the roll gap. This function can be derived from a locally applied empirical spread model, or better from a plasticity approach of lateral spread. Domanti's asymptotic approach to Hill's General Method [3] is used in the following analysis. The Domanti solution is limited to wide flat sections what concerns the absolute width calculation, but the relative spreading function can be used for all types of rolling processes, when it is scaled to a fixed exit width calculated by a precise empirical spread formula. In the next steps, a combination of Marini's spread equation [4] and Domanti's asymptotic model is used for the purpose of the local spread prediction. An example for a typical pass in shown in Fig. 6.

Generally, the absolute spread also depends on the acting interstand tensions. We may formulate this influence in terms of an empirical model reported by Mauk [5] by stating that the total cross-sectional natural strain $\varphi_{A}$ in the pass is given by:

$$
\varphi_{A}=\varphi_{A, 0}+\Delta \varphi_{A, \sigma}
$$

Therefore, we may subdivide the total natural strain $\varphi_{A}$ in a part assuming maximum spread (disregarding tension effects) $\varphi_{A, 0}$ and a tension-influenced strain contribution $\Delta \varphi_{A, \sigma}$. We will express the 
Table 1: Coefficients for the empirical model for the influence of interstand tensions on lateral spread

\begin{tabular}{llll}
\hline$i$ & $m_{i, 1}$ & $m_{i, 2}$ & $m_{i, 3}$ \\
\hline 1 & 1.05502 & 0.100816 & -0.591029 \\
2 & -0.886507 & -0.00258613 & 0.159971 \\
3 & -0.347681 & -0.457338 & 0.0525161 \\
\hline
\end{tabular}

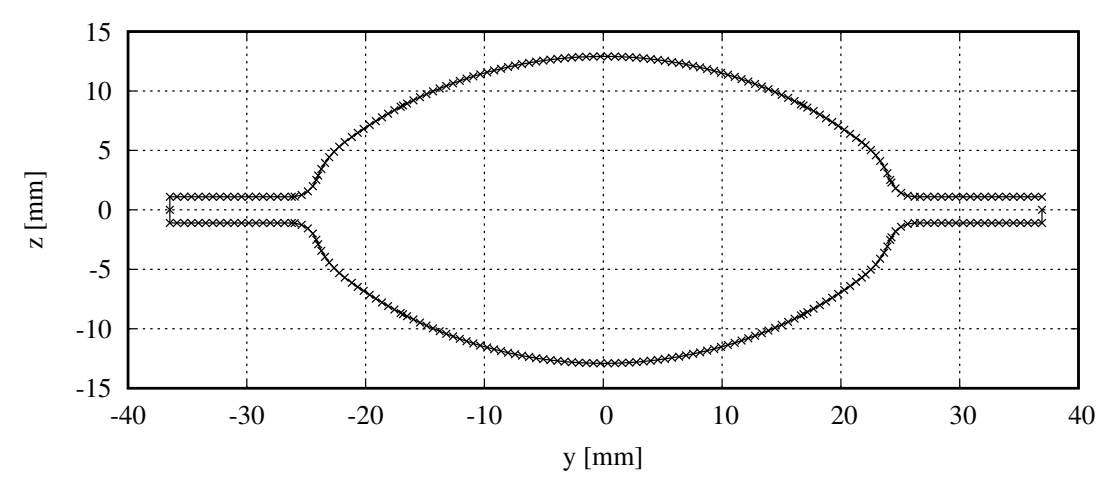

Figure 7: Geometry of a double-radius oval groove by discrete points as a polygonal contour

strain contribution which is influenced by the tensions in an empirical equation as a function of the acting tensions and the geometrical parameters of the rolling process:

$$
\Delta \varphi_{A, \sigma}=k_{1}\left(\frac{t_{0}}{k_{f m}}\right)^{2}+k_{2}\left(\frac{t_{0}}{k_{f m}}\right)+k_{3}\left(\frac{t_{1}}{k_{f m}}\right)
$$

The coefficients in Eqn. (2.22) are functions of the pass geometry:

$$
k_{i}=m_{i, 1} \frac{\Delta h}{h_{0}}+m_{i, 2} \frac{b_{0}}{h_{0}}+m_{i, 3} \frac{A_{d}}{A_{m}}, i=1 \ldots 3
$$

The coefficients $m_{1, i}$ to $m_{3, i}$ are found by linear regression of experimental results taken from various sources. Table 1 shows the coefficients which were found by regression analysis of rolling trials with tensions carried out by and Nikkilä and Treis [7, 10].

With help of these relations, we can use the numerical model for the interstand tension prediction as described in Sec. 2.2 for the prediction of interstand tensions for rolling processes with non-negligible spread effects.

\subsection{Effects of interstand tension in round-oval-round pass sequences}

For rolling processes in wire rod and bar mills, non-cylindrical rolls are used with certain groove geometries to produce the desired product shapes. The calulation of spread and height deformation therefore is more complicated then for rectangular flat sections. Consequently, a rectangular pass method is used to transform the section pass in to an equivalent flat pass. It should be noted that the rectangular pass method has advantages over a direct empirical calculation of spread for section passes, resulting in complicated spread formulae with many empirical factors as given by other authors [8]. The rectangular pass method allows us to employ the theoretical concepts of the flat rolling theory, therefore enabling the interstand tension assessment by the method described in the present paper. To enable a numerical treatment of the non-flat roll and material geometries, these are described by polygonal contours with small step widths. An example is given for a double-radius oval groove shown in Fig. 7. 


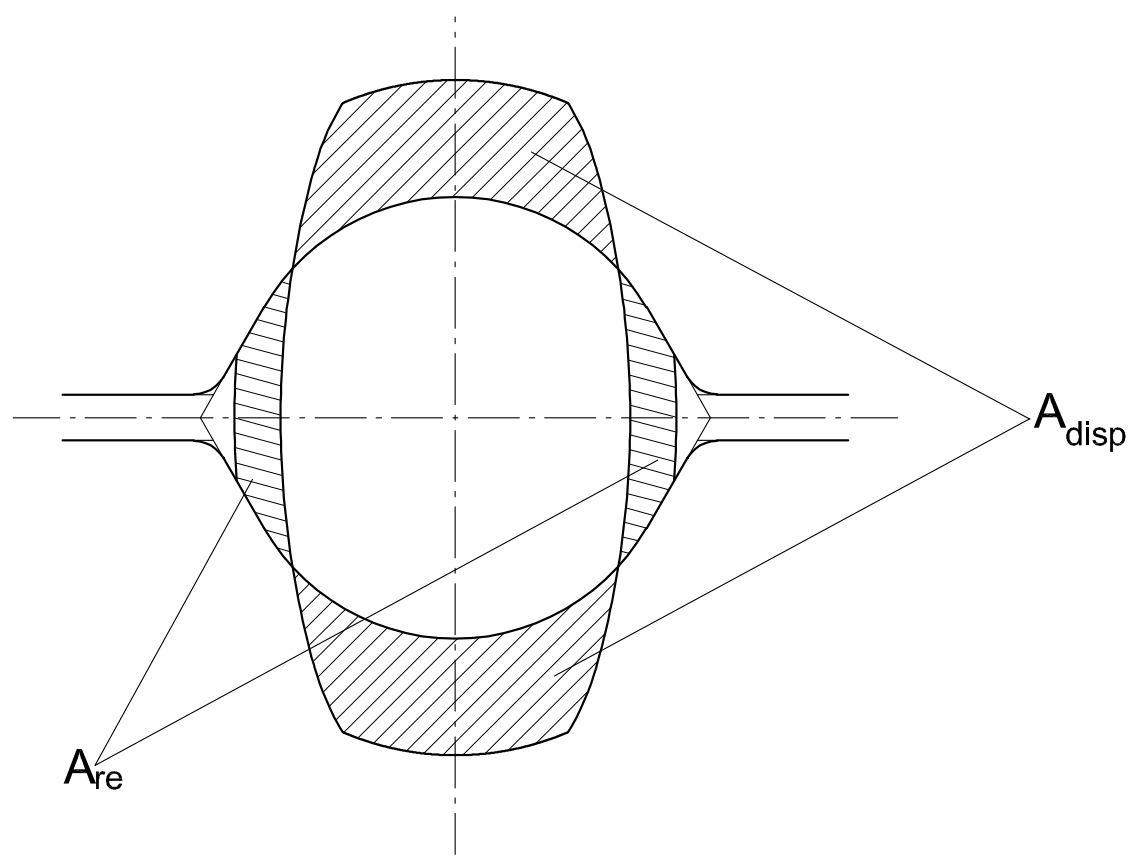

Figure 8: Displaced and reappearing area at a section pass oval to round

By using this approach, arbitrary pass geometries can be handled. The necessary information is given in the form of vectors of the $\mathrm{x}$ and $\mathrm{y}$ coordinates. The geometrical operations needed to calculate the equivalent flat pass and the exit section shapes are implemented using the $\mathbf{x}$ and $\mathbf{y}$ vectors.

For long products like wire rod and bars, the lateral spread has a much higher impact than it has for flat products. We can see from the oval to round pass shown in Fig. 8 that parts of the cross section of the original oval section shape are displaced by the rolls (the displaced surface $A_{d i s p}$ ). We would not be able to form a round section out of the oval entry, if not a part of this displaced surface would form the reappearing surface $A_{r e}$. Therefore, a certain lateral spread must be present in long product rolling and cannot be treated as an undesirable side effect, but it must be effectively controlled.

To assess the effects of interstand tensions on the section shape we use the empirical model described in section 2.3. An example for the results in a round pass is shown in Fig. 9.

The first case (left picture in Fig. 9) represents the reference case free from tensions and disregarding any mill spring, as for a mill stand with an inifite rigidity. Here, a designed groove height of $12.41 \mathrm{~mm}$ is met at a section width of $12.83 \mathrm{~mm}$, yielding a roll force of $83.3 \mathrm{kN}$. In the more realistic case of an elastic mill stand (see right picture) with a rigidity constant of $350 \mathrm{kN} / \mathrm{mm}$, back and front tensions of $29.9 \frac{\mathrm{N}}{\mathrm{mm}^{2}}$ and $56.3 \frac{\mathrm{N}}{\mathrm{mm}^{2}}$ are encountered. These tensions induce a roll force decrease to $63.5 \mathrm{kN}$. Since the stand behaves elastic, the roll force leads to a mill spring that produces an exit height of $12.59 \mathrm{~mm}$. The tensions decrease the lateral spread to a final width of $12.09 \mathrm{~mm}$. Note that all the interacting effects like temperature distribution and subsequent section changes are treated accordingly by the overall model and the coupling of the different mill stands due to mill spring and the tensions are taken into account.

\section{Results of the model for industrial rolling processes}

For all computations presented in this section, a strip material C55 is assumed with a true stress-strain curve following Eqn. (3.1) [6] as a function of the true strain $\varphi$, the strain rate $\dot{\varphi}$ and the deformation temperature $\vartheta$.

$$
k_{f}=k_{0} e^{m_{1} \vartheta} \dot{\varphi}^{m_{2}+m_{5} \vartheta} \varphi^{m_{3}} e^{m_{4} \varphi}
$$




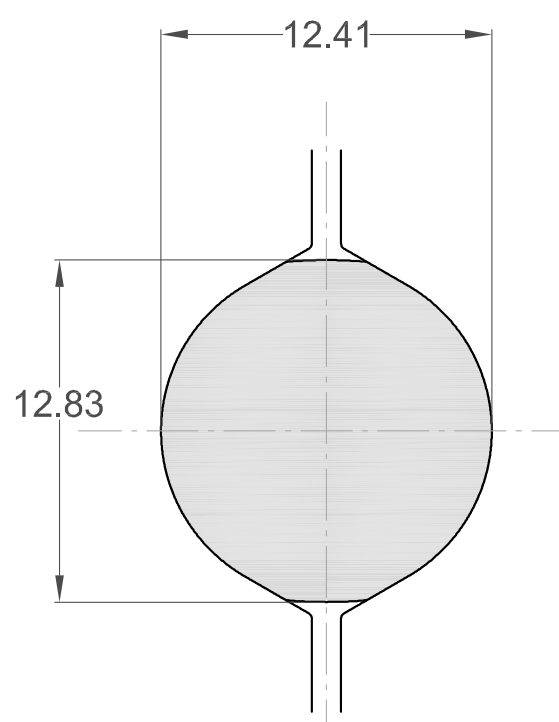

rigid stand

no tensions

roll force: $83.8 \mathrm{kN}$

mean yield stress: $229 \mathrm{~N} / \mathrm{mm}^{2}$

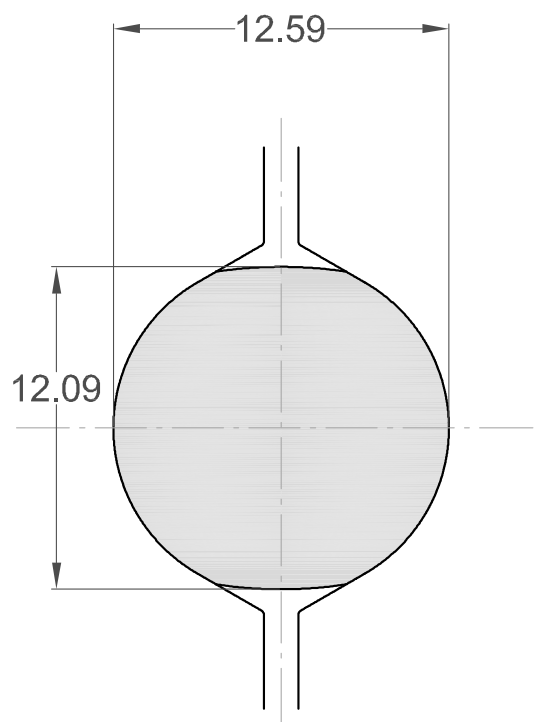

elastic stand, rigidity: $350 \mathrm{kN} / \mathrm{mm}$ roll force: $63.5 \mathrm{kN}$

back tension: $29.9 \mathrm{~N} / \mathrm{mm}^{2}$

front tension: $56.3 \mathrm{~N} / \mathrm{mm}^{2}$

mean yield stress: $223 \mathrm{~N} / \mathrm{mm}^{2}$

Figure 9: Calculated influence of interstand tensions and elastic mill spring on the rolled cross section of a wire rod finishing block

\subsection{Finishing train of a hot strip mill}

We consider a seven-stand finishing train of a hot strip mill, which is designed to work with moderate tensions of $20 \mathrm{~N} / \mathrm{mm}^{2}$ between the stands. A transfer bar with an initial thickness of $h_{0}=40 \mathrm{~mm}$ is reduced to a final strip thickness of $h_{7}=3.0 \mathrm{~mm}$ at a finished rolling speed of $v_{e}=10 \mathrm{~m} / \mathrm{s}$ out of the last mill stand. The pass schedule is given in Table 2.

\subsubsection{Influence of a transfer bar height variation on interstand tensions}

It is known from rolling mill practice, that the height of the transfer bar entering the finishing train influences the interstand tension distribution. This effect can be calculated using the present model. Figure 10 shows the calculated tension distribution for the finishing train, if the initial tranfer bar thickness is varied up to $+/-10$ percent of the reference height of $40 \mathrm{~mm}$.

The reference case returns the originally given tensions of $20 \mathrm{~N} / \mathrm{mm}^{2}$. If the strip entry thickness

Table 2: Pass Schedule of an industrial hot strip mill finishing train

\begin{tabular}{llll}
\hline Pass & $\begin{array}{l}\text { Strip Height } \\
\text { in mm }\end{array}$ & $\begin{array}{l}\text { Roll Diameter } \\
\text { in mm }\end{array}$ & $\begin{array}{l}\text { Front Tension } \\
\text { in } \frac{N}{\mathrm{~mm}^{2}}\end{array}$ \\
\hline Initial & 40.00 & & \\
1 & 26.42 & 600 & 20 \\
2 & 17.74 & 600 & 20 \\
3 & 12.05 & 600 & 20 \\
4 & 8.33 & 600 & 20 \\
5 & 5.84 & 600 & 20 \\
6 & 4.15 & 600 & 20 \\
7 & 3.00 & 600 & 20 \\
\hline
\end{tabular}




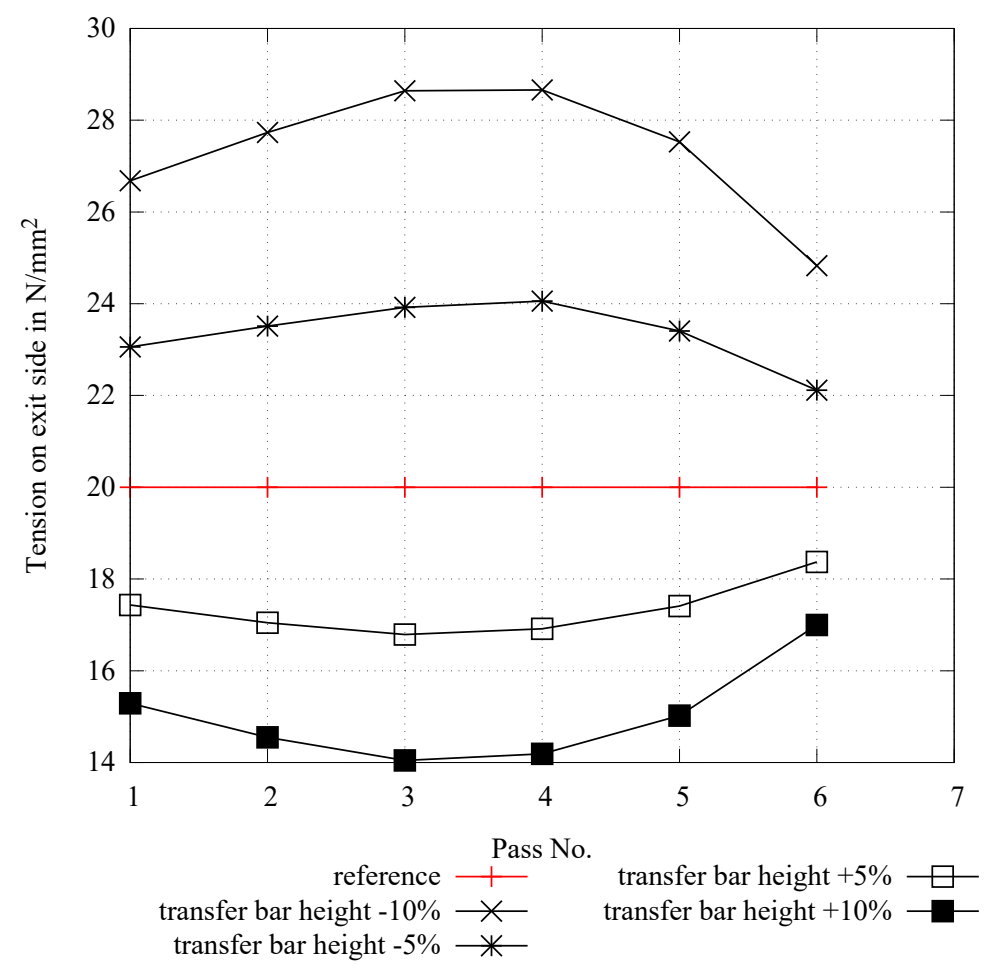

Figure 10: Calculated influence of varying transfer bar thickness on the tension behaviour of the finishing train

is reduced by 10 percent, the tensions rise to values ranging from $26.5 \mathrm{~N} / \mathrm{mm}^{2}$ to a maximum value of $28.5 \mathrm{~N} / \mathrm{mm}^{2}$ In the opposite case, if the entry thickness is increased by 10 percent, the interstand tensions in the finishing train decrease to values between $14 \mathrm{~N} / \mathrm{mm}^{2}$ and $17 \mathrm{~N} / \mathrm{mm}^{2}$.

\subsubsection{Friction influence on the interstand tension distribution}

The interstand tension distribution is expected to vary with the present friction conditions. To examine this effect, the reference case with constant tensions of $20 \mathrm{~N} / \mathrm{mm}^{2}$ and a friction coefficient of $\mu=0.3$ is compared to cases of a varied friction coefficient between $\mu_{\min }=0.25$ and $\mu_{\max }=0.35$. The numerical results of this study are shown in Figure 11.

It can be seen that in the considered cases, a decreasing coefficient of friction leads to increasing interstand tensions. Generally, it can be stated that the friction coefficient does have a high impact on the tension distribution in a continuous rolling mill, as Fig. 11 shows. For the operational practice of a continuous rolling mill, interstand tensions have to be expected to vary extensively with the present friction conditions.

\subsubsection{The influence of the rolling temperature on interstand tensions}

Another effect on the tension distribution to be examined is that of the rolling temperature. Figure 12 shows the tension distributions that result from varied entry temperatures in the finishing train. It is seen that the calculated interstand tensions increase with decreasing rolling temperature.

\subsection{Flat bar mill with lateral spread}

Applying the Equations given in Sec. 2.3, we can calculate the reference state of angular velocities for a given set of interstand tensions, taking into account the lateral spread as well as the tension influence. It is important to note that the resulting tension influence on the designed angular roll velocities originates 


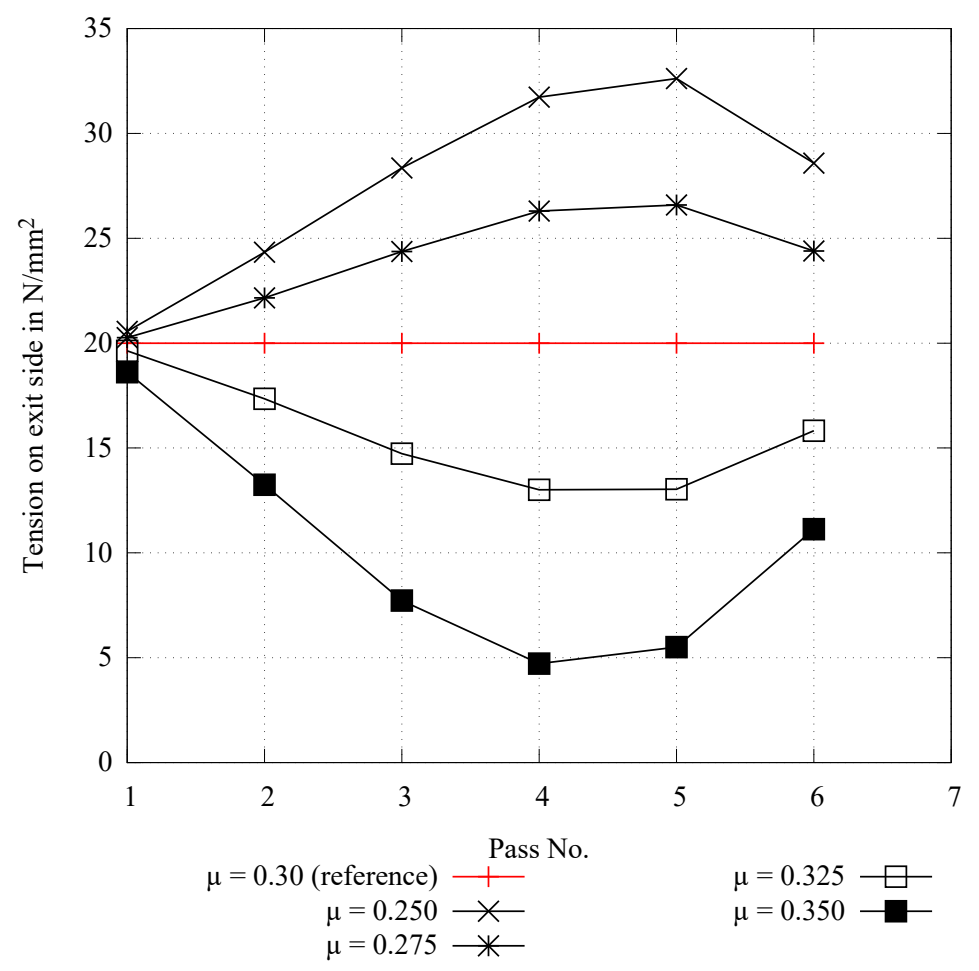

Figure 11: Calculated influence of friction on the tension behaviour of the finishing train

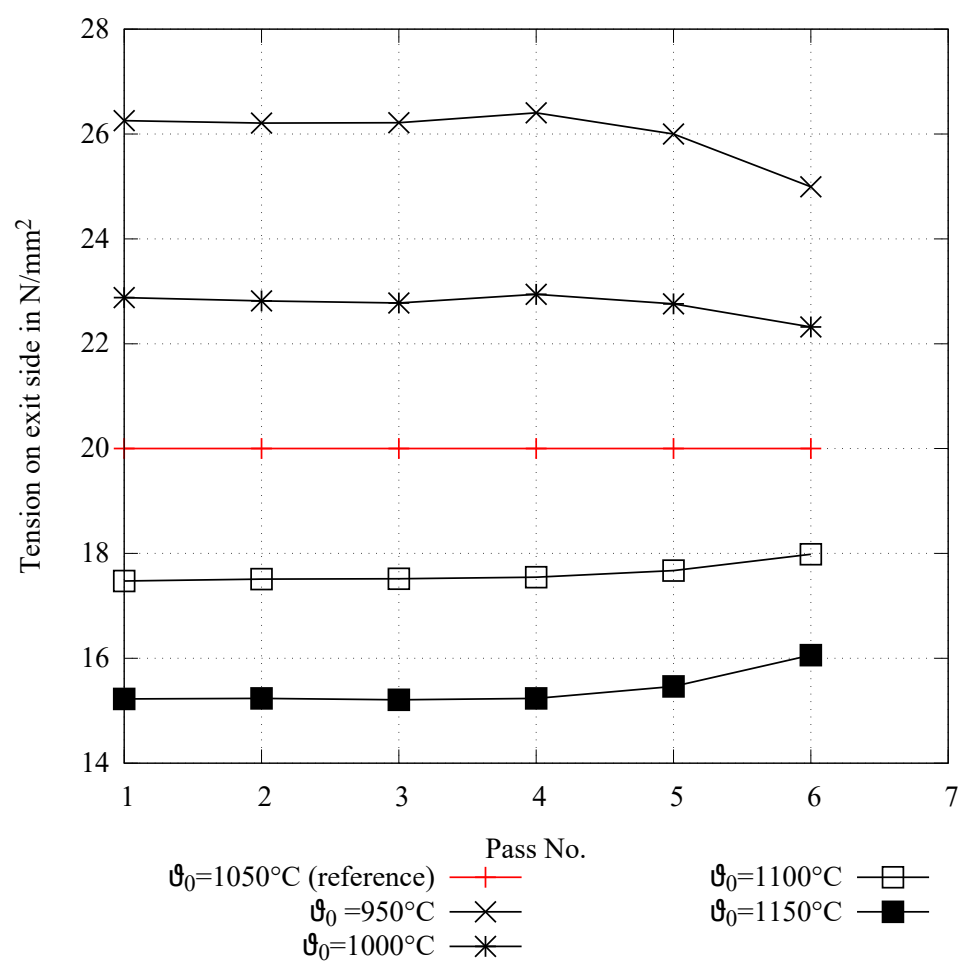

Figure 12: Calculated influence of entry temperature on the tension behaviour of the finishing train 


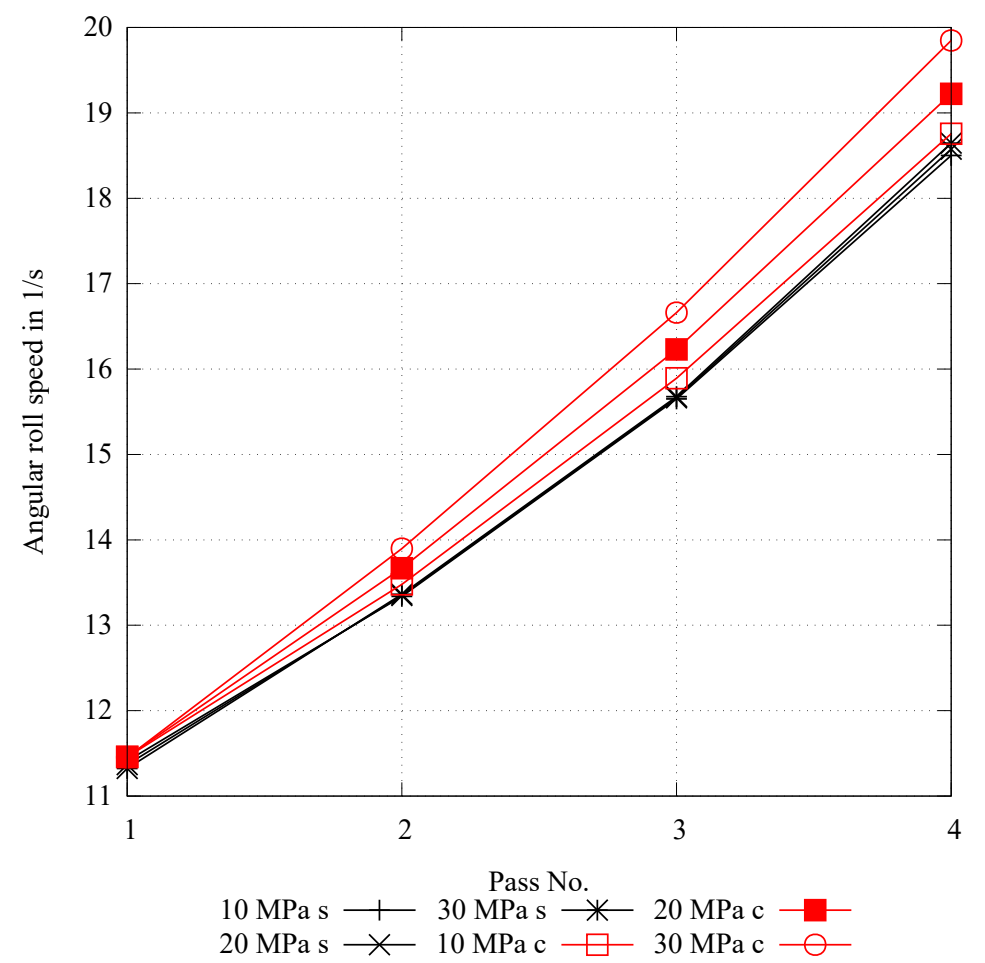

Figure 13: Influence of the interstand tensions on calculated angular roll velocities. s: tension-influence on spread disregarded; c: tension-influence on spread accounted for

from two different effects, the first being the direct influence of the tensions on the shift of the neutral point, the second originating from a distortion of the volume flux, when the spreading and therefore the rolled cross sections are affected by the tensions.

Fig. 13 shows a comparison of the designed roll velocities for the same pass schedule under lateral spread, starting with a 50x50 mm square section, rolled down continuously to a final height of $h_{e}=20 \mathrm{~mm}$. In the Figure, the black curves show the case where the tension-dependency of the lateral spread is disregarded and the tension effects are controlled by the neutral point shift only, where the red curves show the calculations with the tension-influenced spread taken into account. From this comparison, it can be seen that the neutral point effect is small compared to the combined effects.

Fig. 14 shows the resulting section widths for the parameter combinations considered in 13 . The interstand tension leads to a significant decrease of the section widths, which shows effects on the calculated angular roll velocities, cf. Fig. 13.

The inverse calculation of the acting tensions as described in the preceding sections can be carried out in the same way. Fig. 15 shows calculated examples. The black curves represent the interstand tensions in the four-stand mill with the tension influence on lateral spread disregarded. The influence of the entry thickness on the resulting tensions is very high. For the cases with the tension-effects taken in to account represented by the red curves, the overall tension influence is much lower.

\subsection{Single-strand wire rod mill}

For the inverse tension calculation in a wire rod mill, the present model can be used in a way similar to the method presented for flat product rolling. Here, the second intermediate mill of a single-strand wire rod mill will be treated. The roll pass design of this six-stand mill arrangement is shown in Fig. 16. An initial round section with a nominal diameter of $32 \mathrm{~mm}$ is reduced to a final section of $15.5 \mathrm{~mm}$ in diameter, which serves as the entry section to the wire rod finishing block.

First, the angular velocities of the rolls were designed for a reference configuration with interstand 


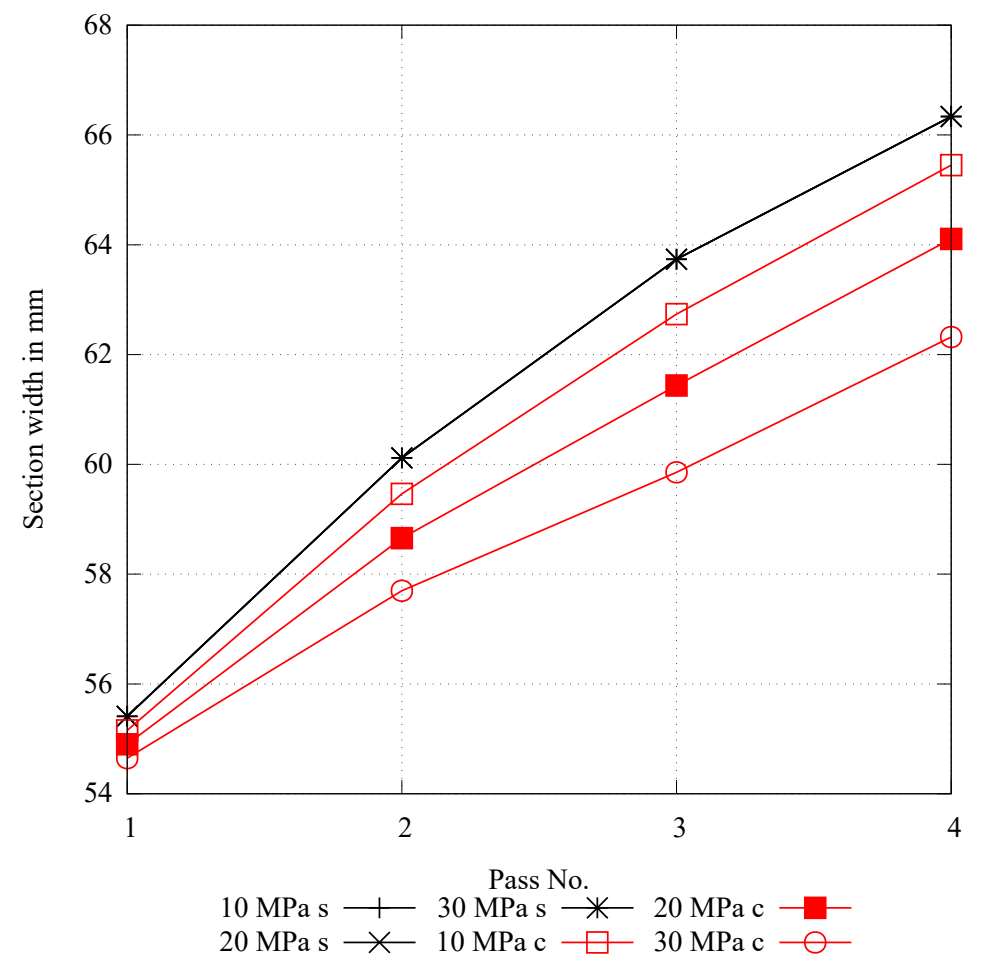

Figure 14: Influence of the interstand tensions on calculated section widths

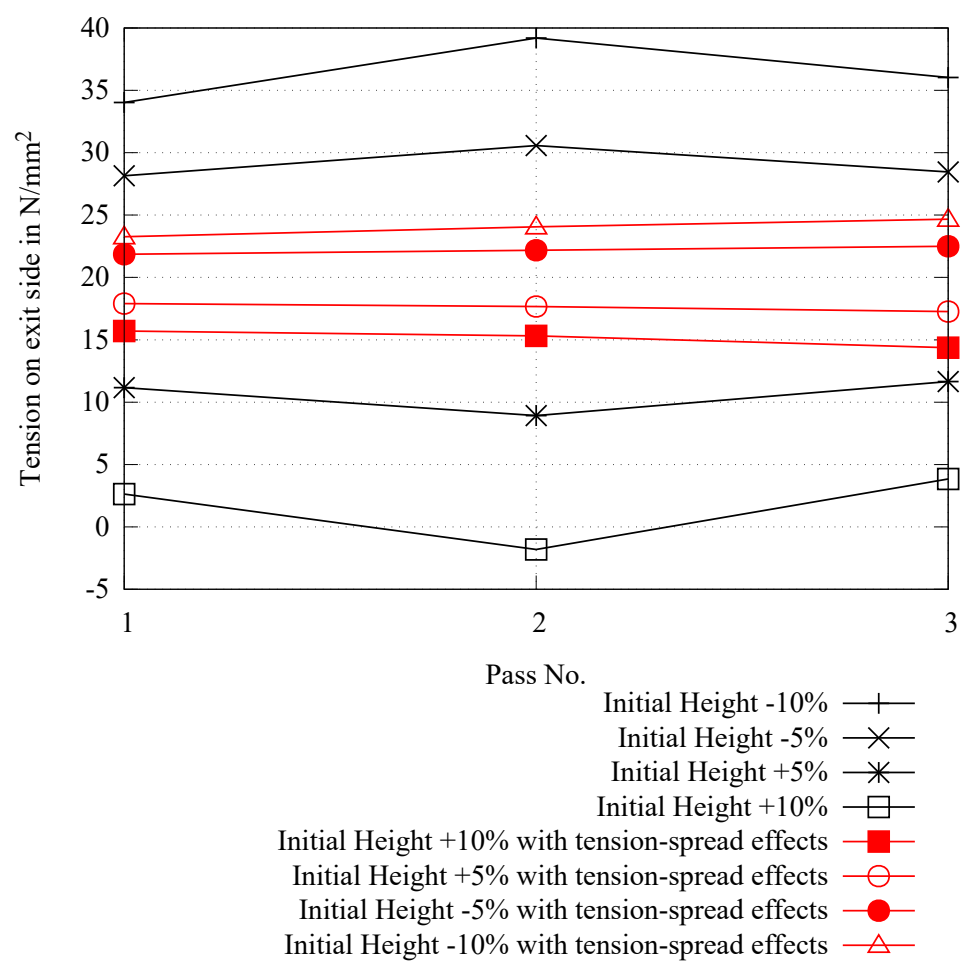

Figure 15: Comnparison of calculated interstand tension distributions with and without tension-influenced spreading effects 


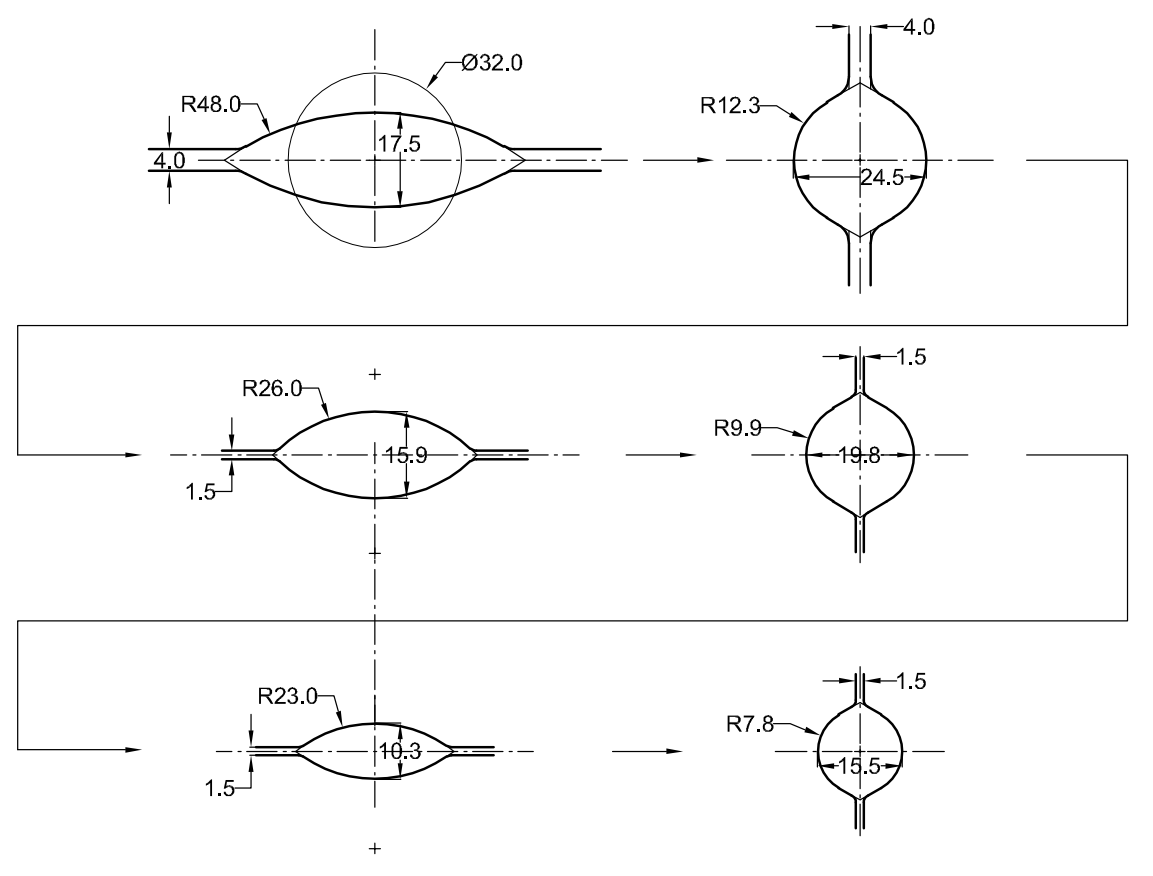

Figure 16: Pass design of the second intermediate mill of a single-strand wire rod mill for the smallest final section

tensions of 10 percent of the flow stress. With the same roll velocities, a parameter study was carried out to examine the influence of a varying entry section on the resulting interstand tensions.

Fig. 17 shows the calculated tensions distributions for a $32 \mathrm{~mm}$ entry (nominal) and two varied entry cross sections of $31.5 \mathrm{~mm}$ and $32.5 \mathrm{~mm}$. From the calculated results we can see that for the bigger entry section, the interstand tension drops and is reduced to a near to zero tension between the last two passes. On the other hand, when the entry section is decresed to $31.5 \mathrm{~mm}$, interstand tension rise to higher values. In Fig. 18 we can see how the deformation process reacts to these changed interstand tensions.

For the reference condition, a close to round exit section is obtained with $15.5 \mathrm{~mm}$ in height and 15.6 $\mathrm{mm}$ in width direction. When the entry section decreases to $31.5 \mathrm{~mm}$, higher tensions are generated. For the final pass, the back tension increases from $21 \frac{\mathrm{N}}{\mathrm{mm}^{2}}$ to $37 \frac{\mathrm{N}}{\mathrm{mm}^{2}}$, see Fig. 17 . The increase of the interstand tensions between all passes results in a significant decrease of the lateral spread in all passes. For this case, a final section with a width of only $15.0 \mathrm{~mm}$ is generated to serve as the starting section for the finishing block. In the opposite case, when the entry section is enlarged to $32.5 \mathrm{~mm}$, the tensions are significantly decreased and the lateral spread will increase (relative to the reference configuration), resulting in an already overfilled round section with a width of $16.4 \mathrm{~mm}$ (see Fig. 18). Note that the angular roll velocities remain constant for all three cases considered, so the calculation results indicate what deviations of the final sections have to be expected when the initial section undergoes the discussed variations under operation.

To enable a non-faulty rolling process for the $32.5 \mathrm{~mm}$ initial section, the roll velocities must be adjusted by forward-evaluation of the model. Table 3 shows the original and optimized angular roll velocities.

The variations of the nominal $15.5 \mathrm{~mm}$ entry to the finishing block will also effect the rolling process in the finishing block in a similar way as discussed for the intermediate mill. In the finishing block of a wire rod mill, the final rolling speed for the smallest section can be up to $120 \mathrm{~m} / \mathrm{s}$, ensuring an economic production. The vast majority of today's wire rod mills utilize 10-stand finishing blocks with a fixed gear system and a common drive for all stands. In this situation, the rotational speeds of all rolls remain in a fixed relation and it is not possible to control the interstand tensions during operation by changing the rotational speed of one stand relative to the other ones. Because of this fact, the wire rod finishing block is an interesting industrial example to be studied using the new tension calculation model.

Fig. 19 shows the principal pass design of the ten-stand finishing block for the nominal output section 


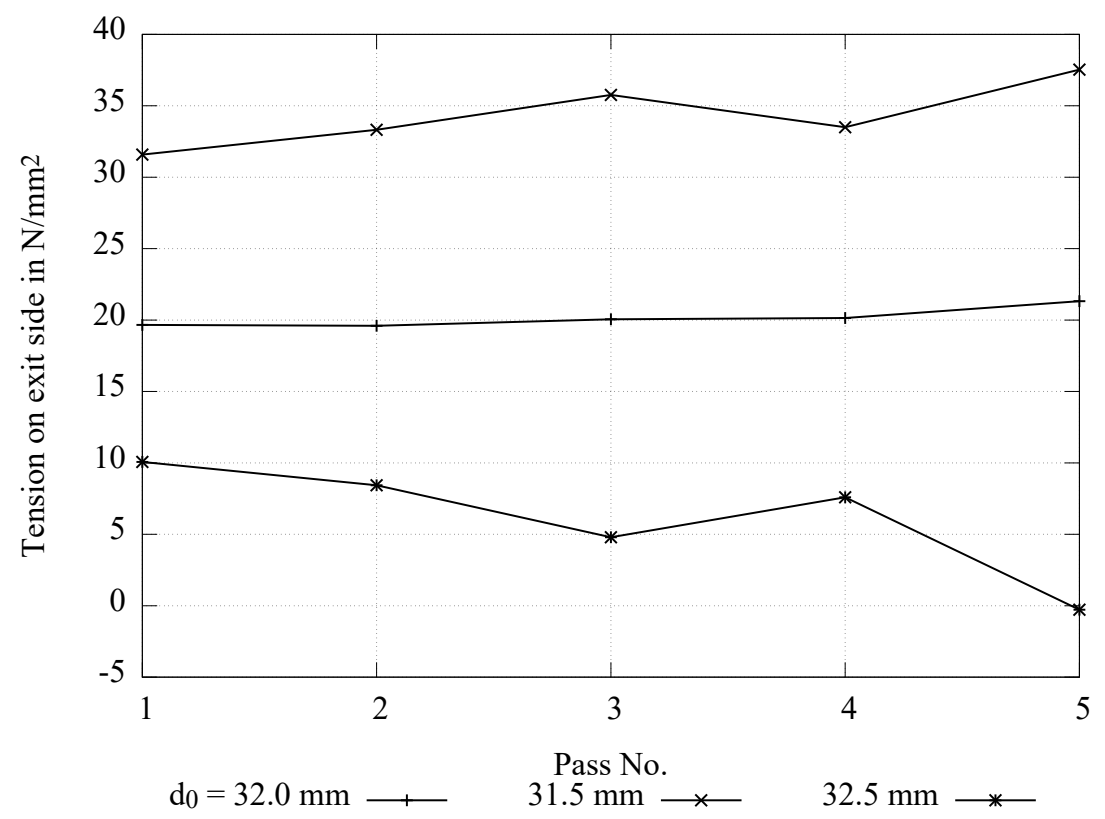

Figure 17: Calculated interstand tension distribution in the Intermediate Mill 2 for varied entry sections

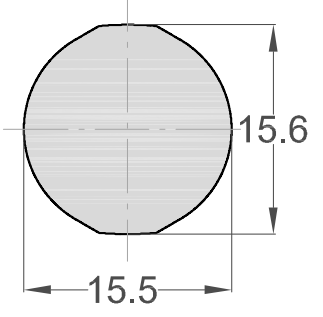

Initial: $32.0 \mathrm{~mm}$

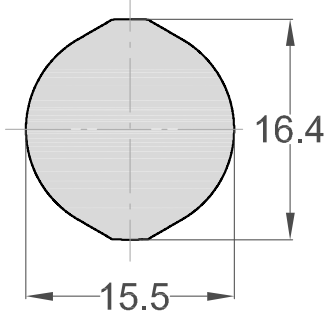

Initial: $32.5 \mathrm{~mm}$

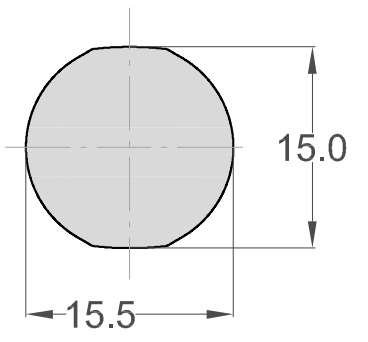

Initial: $31.5 \mathrm{~mm}$

Figure 18: Calculated exit section running out of the second intermediate mill for a $+/-0.5$ mm variation in the entry section

Table 3: Model-based optimizaion of angular roll velocities. $\omega$ : original angular roll velocity

\begin{tabular}{|c|c|c|c|c|}
\hline Pass & $\begin{array}{l}\omega \\
\text { in } s^{-1}\end{array}$ & $\begin{array}{l}\omega^{*} \\
\text { in } s^{-1}\end{array}$ & $\begin{array}{l}t_{i, 1} \\
\text { in } N / m m^{2}\end{array}$ & $\begin{array}{l}t_{i, 1}^{*} \\
N / m m^{2}\end{array}$ \\
\hline 1 & 28.20 & 27.48 & 10.07 & 25.9 \\
\hline 2 & 37.31 & 37.28 & 8.43 & 25.7 \\
\hline 3 & 64.90 & 65.03 & 4.79 & 25.9 \\
\hline 4 & 81.12 & 81.77 & 7.60 & 25.8 \\
\hline 5 & 97.15 & 97.51 & -0.28 & 27.4 \\
\hline 6 & 128.08 & 128.56 & 0.0 & 0.0 \\
\hline
\end{tabular}



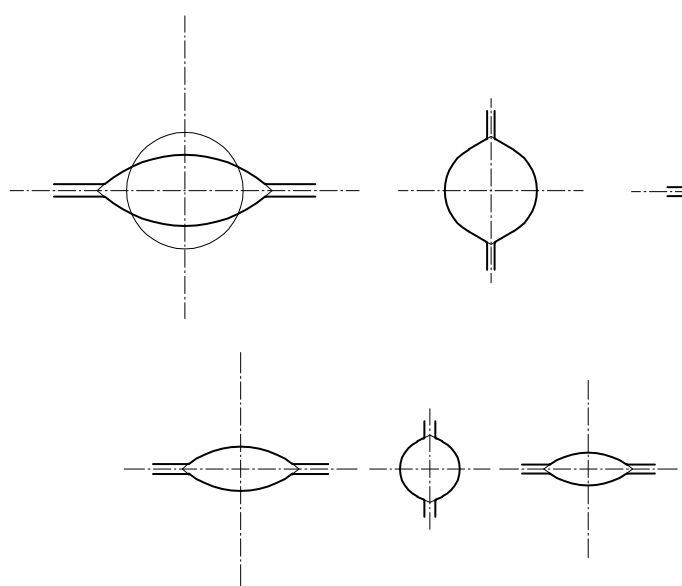
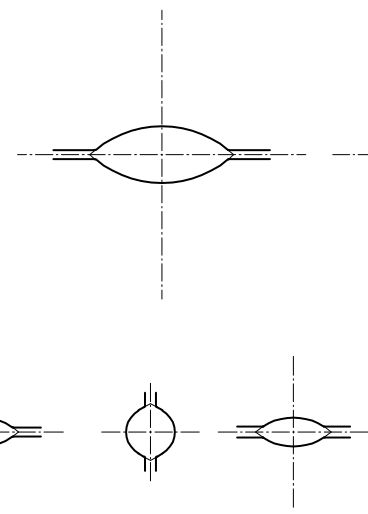
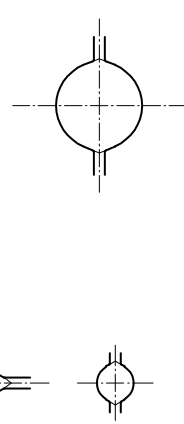

Figure 19: Pass design of a ten-stand wire rod finishing block for a $5.0 \mathrm{~mm}$ rod out of a nominal $15.5 \mathrm{~mm}$ initial section

Table 4: Groove data for the 10-stand finishing block

\begin{tabular}{lllll}
\hline Pass & Type & $\begin{array}{l}\text { Height } \\
\text { in mm }\end{array}$ & $\begin{array}{l}\text { Radius } \\
\text { in mm }\end{array}$ & $\begin{array}{l}\text { Roll Gap } \\
\text { in mm }\end{array}$ \\
\hline Initial & Section & 15.5 & 7.75 & \\
1 & Oval & 9.5 & 16.5 & 1.6 \\
2 & Round & 12.24 & 6.3 & 0.94 \\
3 & Oval & 7.6 & 14.0 & 1.2 \\
4 & Round & 10.0 & 5.1 & 1.3 \\
5 & Oval & 6.0 & 11.5 & 1.3 \\
6 & Round & 8.0 & 4.08 & 1.5 \\
7 & Oval & 4.40 & 9.0 & 1.2 \\
8 & Round & 6.50 & 3.31 & 1.5 \\
9 & Oval & 3.85 & 7.5 & 1.45 \\
10 & Round & 5.00 & 2.55 & 1.4 \\
\hline
\end{tabular}

of $5.0 \mathrm{~mm}$ with details of the groove geometries given in Table 4 .

In a parametric study, the initial round section of the finishing block was varied between $15.0 \mathrm{~mm}$ and $15.7 \mathrm{~mm}$, where the nominal design condition is a $15.5 \mathrm{~mm}$ round section. Fig. 20 shows the interstand tension distributions that are encountered for the different conditions. The typical shape of these distributions follows from the mill spring which is strongly connected to the reduction distribution of the finishing block, featuring higher reductions in the oval passes than in the round passes, and as a conclusion higher roll forces and mill spring. For the smallest entry section considered $(15.0 \mathrm{~mm})$, very high tensions of up to $81 \frac{\mathrm{N}}{\mathrm{mm}^{2}}$ are encountered, where for the biggest entry section of $15.7 \mathrm{~mm}$, the tensions are decreased very much with a small compression stress between the first two passes.

Fig. 21 shows the final sections which must be expected for the different entry section conditions, where the back tensions for the final pass are given in Table 5 .

Generally, we can observe that the height of the final section is not severely affected by the entry section, as the tension variation generates force and therefore mill spring variations of the final pass when the screw-down remains fixed. In contrast, the section width, being controlled by the acting tension directly, varies between $4.62 \mathrm{~mm}$ for the $15 \mathrm{~mm}$ entry section up to $5.18 \mathrm{~mm}$ for the $15.7 \mathrm{~mm}$ entry section. 


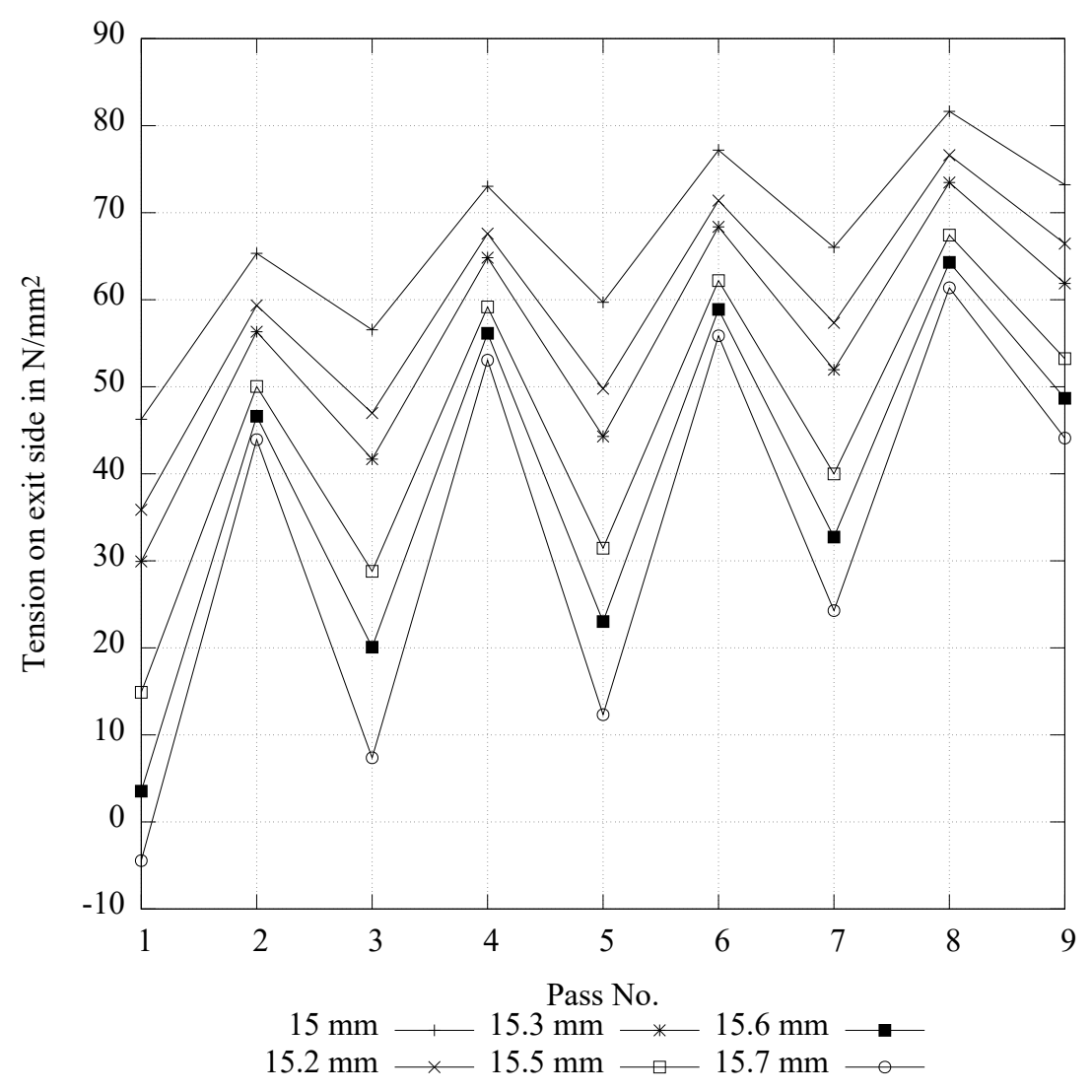

Figure 20: Interstand tension distribution in a 10-stand wire rod finishing block

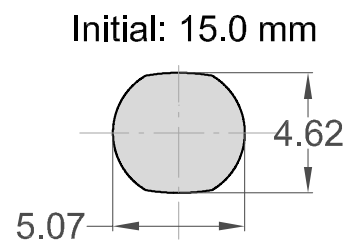

Initial: $15.5 \mathrm{~mm}$

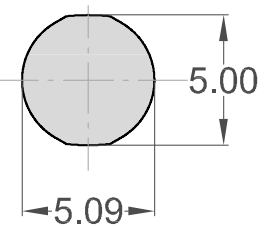

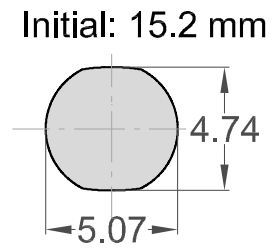

Initial: $15.6 \mathrm{~mm}$

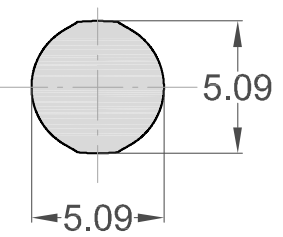

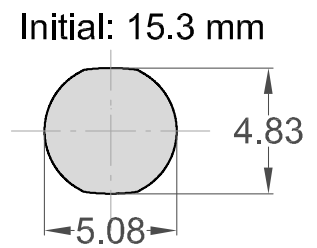

Initial: $15.7 \mathrm{~mm}$

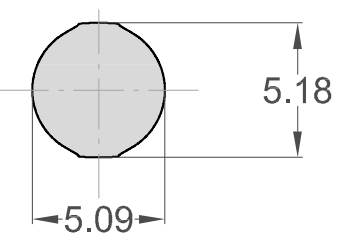

Figure 21: Calculated final sections of the $5 \mathrm{~mm}$ wire rod as a function of the entry diameter to the finishing block 
Table 5: Metal forming data for the exit sections given in Fig. 21

\begin{tabular}{llll}
\hline $\begin{array}{l}\text { Entry Diameter } \\
\text { in } \mathrm{mm}\end{array}$ & $\begin{array}{l}\text { Back Tension } \\
\text { in } \frac{N}{m m^{2}}\end{array}$ & $\begin{array}{l}\text { Height } \\
\text { in } \mathrm{mm}\end{array}$ & $\begin{array}{l}\text { Width } \\
\text { in } \mathrm{mm}\end{array}$ \\
\hline 15.0 & 73.2 & 5.07 & 4.62 \\
15.2 & 66.5 & 5.07 & 4.74 \\
15.3 & 61.9 & 5.08 & 4.83 \\
15.5 (nom.) & 53.2 & 5.09 & 5.00 \\
15.6 & 48.7 & 5.09 & 5.09 \\
15.7 & 44.1 & 5.09 & 5.18 \\
\hline
\end{tabular}

\section{Discussion}

In the present paper, a computational model for the inverse calculation of interstand tensions in continuous rolling mills was introduced using iterative calculations with a rolling model and a linearization of tensionroll velocity relationship. This relationship is formulated internally as a composite function with the neutral angle of the roll gap as central coupling parameter between statics and kinematics of the rolling process. For the simplest case of negligible lateral spread, calculations for a seven-stand finishing train of a hot strip mill were carried out. It is seen that the interstand tensions depend significantly on the entry height of the transfer bar and on the friction coefficient. A temperature influence of the interstand tensions can also be observed using the model, but it should be clearly understood that the effect observed here is mainly controlled by the temperature-dependency of the material's flow curve. The true temperature dependency observed in rolling mill practice will be a combined effect of flow stress and a temperature dependent friction coefficient.

In the next step, the model was applied to a flat rolling pass schedule with apparent lateral spread. An empirical model is used to describe the influence of the tensions upon the lateral spread, an effect which leads to extra nonlinearities in the developed numerical model. It is therefore necessary to introduce a relaxation factor into the model as to ensure a stable convergence. It is shown, that the inclusion of the tension-spread influence leads to a significant deviation of the calculation results to the case where the spread is treated being independent of the tensions.

The results of this study indicate that interstand tensions are of great importance also in rolling mills for long products. To illustrate this, another study was carried out for a single-strand wire rod mill, where the influence of varying entry sections into the intermediate mill and the finishing block are discussed. In the intermediate mill, the tensions and section formations depend largely on the entry section. It was shown that not only a too big entry section may lead to overspreading in the last passes, but also to very small tensions. Even compressive stresses may be observed, which can lead to mill cobbles and must be avoided. This effect can be counteracted by active steering of the angular roll velocities to ensure higher tensions. For a wire rod finishing block, the model calculations revealed that a precise sizing of the entry section is important to avoid excessive variations in the interstand tensions encountered, as an active control of the angular roll speeds is impossible due to the fixed gear system of the finishing block.

It may be concluded that interstand tensions are a principal influence parameter for rolling processes in continuous rolling mills and therefore must be observed and controlled carefully. In rolling of long products, they play a major role on the achievable product tolerances, since the rolled cross sections can be effectively controlled by a targeted adjustment of the tensions.

As a significant influence of friction on the interstand tension was shown, it is important to develop a method for a reliable online-measurement of the coefficient of friction during hot rolling in the near future. These method should be based on optical measurements of the forward slip and section formation, as not to disturb the rolling process. Also, the various influences of the coefficient of friction on temperature, rolling velocity and material pairing (rolls and workpiece) should be worked out using an inline-measurement method to form a better theoretical basis for the description of the friction influence on the lateral spread and side formation.

In the future developments of data-driven modeling and control techniques for rolling mills based on digital twins, a precise and fast tension calculation model will play a major role. 


\section{References}

[1] J. M. Alexander. "On the Theory of Rolling". Proceedings of the Royal Society 326.1567 (1972). Pp. 535-563. DOI: 10.1098/rspa.1972.0025.

[2] S. Chen, W. Li, and X. Liu. "Calculation of rolling pressure distribution and force based on improved Karman equation for hot strip mill". International Journal of Mechanical Sciences 89 (2014). Pp. 256-263. ISSN: 00207403. DOI: 10.1016/j.ijmecsci.2014.09.011.

[3] S. Domanti, D. L. S. McElwain, and R. H. Middleton. "Asymptotic Approach to the Hill Model of Spread in Rolling". Journal of Engineering Materials and Technology 117.1 (1995). P. 75. ISSN: 00944289. DOI: $10.1115 / 1.2804374$.

[4] N. Marini. "Nuova teoria sulla laminazione". La Metallurgia Italiana (1941). Pp. 292-309.

[5] P. J. Mauk. Analysis of interacting influence parameters on the tolerances of wire rod and bars in the rolling process. Erlangen, 1999.

[6] P. J. Mauk and J. Gottschling. "Hot Flow Curves of Metallic Materials". Proceedings 14th international forgemasters meeting, IFM 3 (2000). P. 2000.

[7] K. Nikkilä. "On the Effects of Front and Back Tensions on Wire Rod Rolling". Dissertation. Helsinki: Helsinki University of Technology, 1977.

[8] M. Schmidtchen, P. Adamyanets, and R. Kawalla. "Model Approaches for Simulation of Processes in Rod and Wire Production". Materials Science Forum 892 (2017). Pp. 34-43. IsSN: 1662-9752. DOI: 10.4028/www. scientific.net/MSF.892.34.

[9] G. Spur and T. Stöferle, eds. Handbuch der Fertigungstechnik: Umformen. Vol. 2/1. München: Carl Hanser, 1983. ISBN: 3-446-12533-7.

[10] H. Treis. "Ermittlung der Formänderungsverhältnisse beim Warmwalzen auf der Flachbahn ohne und mit äußerem Längszug". Dissertation. Aachen: RWTH Aachen, 1968. 